\title{
RESEARCH
}

Open Access

\section{Immunoregulatory potential of mesenchymal stem cells following activation by macrophage-derived soluble factors}

Laura Saldaña ${ }^{1,2^{*}}$ DD, Fátima Bensiamar ${ }^{1,2}$, Gema Vallés $^{1,2}$, Francisco J. Mancebo ${ }^{1,2}$, Eduardo García-Rey ${ }^{2,3}$ and Nuria Vilaboa ${ }^{1,2}$

\begin{abstract}
Background: Immunoregulatory capacity of mesenchymal stem cells (MSC) is triggered by the inflammatory environment, which changes during tissue repair. Macrophages are essential in mediating the inflammatory response after injury and can adopt a range of functional phenotypes, exhibiting pro-inflammatory and anti-inflammatory activities. An accurate characterization of MSC activation by the inflammatory milieu is needed for improving the efficacy of regenerative therapies. In this work, we investigated the immunomodulatory functions of MSC primed with factors secreted from macrophages polarized toward a pro-inflammatory or an anti-inflammatory phenotype. We focused on the role of TNF- $a$ and IL-10, prototypic pro-inflammatory and anti-inflammatory cytokines, respectively, as priming factors for MSC.
\end{abstract}

Methods: Secretion of immunoregulatory mediators from human MSC primed with media conditioned by human macrophages polarized toward a pro-inflammatory or an anti-inflammatory phenotype was determined. Immunomodulatory potential of primed MSC on polarized macrophages was studied using indirect co-cultures. Involvement of TNF- $\alpha$ and IL-10 in priming MSC and of $\mathrm{PGE}_{2}$ in MSC-mediated immunomodulation was investigated employing neutralizing antibodies. Collagen hydrogels were used to study MSC and macrophages interactions in a more physiological environment.

Results: Priming MSC with media conditioned by pro-inflammatory or anti-inflammatory macrophages enhanced their immunomodulatory potential through increased $\mathrm{PGE}_{2}$ secretion. We identified the pro-inflammatory cytokine TNF-a as a priming factor for MSC. Notably, the anti-inflammatory IL-10, mainly produced by pro-resolving macrophages, potentiated the priming effect of TNF-a. Collagen hydrogels acted as instructive microenvironments for MSC and macrophages functions and their crosstalk. Culturing macrophages on hydrogels stimulated anti-inflammatory versus pro-inflammatory cytokine secretion. Encapsulation of MSC within hydrogels increased $\mathrm{PGE}_{2}$ secretion and potentiated immunomodulation on macrophages, attenuating macrophage pro-inflammatory state and sustaining antiinflammatory activation. Priming with inflammatory factors conferred to MSC loaded in hydrogels greater immunomodulatory potential, promoting anti-inflammatory activity of macrophages.

(Continued on next page)

\footnotetext{
* Correspondence: laura.saldana@salud.madrid.org

${ }^{1}$ Hospital Universitario La Paz-IdiPAZ, Paseo de la Castellana 261, 28046

Madrid, Spain

${ }^{2}$ Centro de Investigación Biomédica en Red de Bioingeniería, Biomateriales y

Nanomedicina, CIBER-BBN, Madrid, Spain

Full list of author information is available at the end of the article
}

(c) The Author(s). 2019 Open Access This article is distributed under the terms of the Creative Commons Attribution 4.0 International License (http://creativecommons.org/licenses/by/4.0/), which permits unrestricted use, distribution, and reproduction in any medium, provided you give appropriate credit to the original author(s) and the source, provide a link to the Creative Commons license, and indicate if changes were made. The Creative Commons Public Domain Dedication waiver (http://creativecommons.org/publicdomain/zero/1.0/) applies to the data made available in this article, unless otherwise stated. 
(Continued from previous page)

Conclusions: Factors secreted by pro-inflammatory and anti-inflammatory macrophages activated the immunomodulatory potential of MSC. This was partially attributed to the priming effect of TNF-a and IL-10. Immunoregulatory functions of primed MSC were enhanced after encapsulation in hydrogels. These findings may provide insight into novel strategies to enhance MSC immunoregulatory potency.

Keywords: Mesenchymal stem cells, Immunomodulation, Macrophage polarization, Cytokines, Priming, Hydrogels, Tissue repair

\section{Background}

The inflammatory response to tissue injury is essential for the correct restoration of tissue structure and function. However, an uncontrolled or unresolved inflammatory process can lead to chronic inflammation and further tissue damage. Macrophages are key regulators of wound healing and are involved in both advancing and resolving inflammation by secreting multiple cytokines and growth factors. Macrophages exhibit functional transitions as tissue repair progresses and can adopt a wide spectrum of phenotypes. Two of the best-characterized phenotypes are pro-inflammatory or M1-like phenotype and antiinflammatory or M2-like phenotype. M1 macrophages produce high levels of pro-inflammatory cytokines and are related to the early stage of inflammation whereas M2 macrophages, with lower pro-inflammatory cytokine production, are associated with the resolution of inflammation and tissue repair [1]. There is evidence that macrophages can display more complex phenotypes with traits associated with both M1 and M2 activation states [2, 3]. In addition, mixed populations of macrophages have been identified $[4,5]$. Functional repolarization of macrophages toward an anti-inflammatory phenotype ensures proper return to homeostasis after injury and is mediated by a large panel of mediators including prostaglandin $\mathrm{E}_{2}\left(\mathrm{PGE}_{2}\right)$ [6]. Several studies suggest that an incorrect balance between M1- and M2-like activities after injury can lead to persistent inflammation and/or maladaptive repair processes, both contributing to aberrant tissue repair $[7,8]$. Due to their critical role during wound healing, macrophages have emerged as potential targets in therapeutic tissue regeneration strategies [9].

Accumulating evidence suggests that mesenchymal stem cells (MSC) promote tissue repair and regeneration through modulation of immune response and secretion of growth factors rather than by replacement of damaged cells. MSC release a wide range of immunoregulatory factors including $\mathrm{PGE}_{2}$ and interleukin-6 (IL-6) that skew macrophages toward a pro-resolving profile [10]. Immunoregulatory capacity of MSC is not constitutive, but depends on a process of "licensing" that implies the activation of MSC by the inflammatory milieu. Thus, in response to inflammatory mediators, MSC produce soluble factors that regulate the immune response. The requirement of MSC activation to induce immunoregulation is supported by data showing that suppression of T cells proliferation induced by MSC in co-cultures was only achieved after addition of sufficient levels of interferon- $\gamma$ (IFN- $\gamma$ ) and tumor necrosis factor- $\alpha$ (TNF- $\alpha$ ) [11-13]. Macrophages plasticity leads to changes in the balance between pro-inflammatory and anti-inflammatory factors as tissue is healed and remodeled. The earliest events trigger the release of numerous pro-inflammatory mediators, which are followed by a shift to increased production of anti-inflammatory cytokines and growth factors to allow tissue repair [14]. Additionally, pro-inflammatory and anti-inflammatory cytokine expression can be induced simultaneously at early stages of inflammation [15]. Given the variability of macrophage activation states throughout the course of inflammation and tissue repair, it is expected that MSC establish interactions with different macrophage phenotypes and that both pro-inflammatory and anti-inflammatory cytokines influence MSC-mediated immunomodulation. To date, the effects of the cocktail of factors originated from pro-inflammatory or anti-inflammatory macrophage populations on immunomodulatory properties of MSC have not been described.

MSC, like all somatic tissues, express human leukocyte antigens (HLA) class I constitutively and have the ability to express HLA class II when exposed to inflammatory factors. The HLA class I antigens are associated with the activation of CD8+ $\mathrm{T}$ lymphocytes while HLA class II antigens are recognized by $\mathrm{CD} 4+\mathrm{T}$ lymphocytes. MSC appear to evade immune rejection by modulating $\mathrm{T}$ cell phenotype and immunosuppressing the local environment. A number of clinical trials involving allogeneic MSC transplantation have shown overall safety and potential effectiveness [16]. MSC have been employed in the clinical treatment of graft-versus-host disease (GvHD) due to their ability to inhibit proliferation and cytotoxic activity of immune system cells. A limited number of clinical trials have reported humoral alloimmunization in human subjects receiving mismatched MSC, but it remains unclear whether this has an impact on their therapeutic efficacy [17]. There is growing interest in combining MSC 
with hydrogels prepared with extracellular matrix (ECM) proteins that resemble the microenvironments where they reside in order to prolong cell survival, potentiate their function, and prevent rejection by the host $[18,19]$. In this work, we extensively investigated the immunomodulatory functions of human MSC activated with secreted factors from human monocyte-derived macrophages polarized toward a pro-inflammatory or an anti-inflammatory phenotype using standard two-dimensional (2D) culture conditions. We focused on the role of TNF- $\alpha$ and IL-10, prototypic pro-inflammatory and anti-inflammatory cytokines, respectively, as priming factors for MSC. Immunoregulatory potential of MSC was evaluated in co-cultures with pro-inflammatory or anti-inflammatory macrophage populations. The assays that led to the most informative data were then performed using MSC encapsulated in collagen hydrogels, which represent a more physiological relevant model.

\section{Methods}

\section{Isolation and culture of primary human macrophages}

Buffy coats were obtained from 30 healthy blood donors, as anonymously provided by the Comunidad de Madrid Blood Bank (Madrid, Spain). Ethical approvals for all blood sources and processes used in this study were approved by the Human Research Committee of Hospital Universitario La Paz (Date of Approval: 03/06/2015). All experiments were carried out in accordance with the approved guidelines and regulations. Human peripheral blood mononuclear cells (PBMC) were isolated from buffy coats by density gradient centrifugation using Ficoll-Paque Plus (GE Healthcare Bio-sciences, Uppsala, Sweden). For monocyte isolation, PBMC were seeded at a density of $15 \times 10^{6} /$ well in six-well plates and allowed to adhere for $1 \mathrm{~h}$ in serum-free RPMI (Lonza, Basel, Switzerland). Adherent cells were cultured for 7 days in RPMI supplemented with $10 \%(v / v)$ heat-inactivated fetal bovine serum (FBS) and $200 \mathrm{U} / \mathrm{ml}$ of granulocyte macrophage-colony stimulating factor (GM-CSF) or $20 \mathrm{ng} / \mathrm{ml}$ macrophage-colony stimulating factor (M-CSF) (both from Peprotech, London, UK). Cytokines were added every 2 days. Macrophages generated in the presence of GM-CSF or M-CSF are referred to as $\mathrm{M} \Phi_{\mathrm{GM}}$ and $\mathrm{M} \Phi_{\mathrm{M}}$, respectively. Conditioned media (CM) were obtained from $M \Phi_{\mathrm{GM}}$ or $\mathrm{M} \Phi_{\mathrm{M}}$ that were treated or not with $10 \mathrm{ng} / \mathrm{ml}$ lipopolysaccharide (LPS) (Sigma, Madrid, Spain) for $90 \mathrm{~min}$, washed three times with phosphatebuffered saline (PBS), and cultured in RPMI medium supplemented with $10 \% \mathrm{FBS}$ for $5 \mathrm{~h}$. The CM were clarified by centrifugation at $1200 \mathrm{~g}$ for $10 \mathrm{~min}$. The experimental scheme used to generate CM is shown in Fig. 1a.

\section{MSC culture and co-culture with macrophages}

Purified human bone marrow-derived MSC were purchased from Lonza and expanded in a defined medium
(Lonza) consisting of basal medium and supplement mix. All experiments were performed between passages 5 and 7 using cells isolated from six different donors aged 18-30 years. $10^{5}$ MSC were seeded in the upper chamber of a 24-mm-diameter transwell insert with 0.4- $\mu \mathrm{m}$ pores (Corning, Lowell, MA, USA) and incubated for $48 \mathrm{~h}$ in $3 \mathrm{ml}$ of DMEM supplemented with $15 \%(v / v)$ heat-inactivated FBS or in $3 \mathrm{ml}$ of a mixture of equal volumes of DMEM with 15\% FBS and CM from macrophages. When indicated and prior to addition to MSC, CM were incubated for $1 \mathrm{~h}$ at $37^{\circ} \mathrm{C}$ with $1 \mu \mathrm{g} / \mathrm{ml}$ neutralizing antibody against TNF- $\alpha$ or IL-10 (Biolegend, San Diego, CA, USA). Parallel sets of MSC were treated for $48 \mathrm{~h}$ with 1 or $10 \mathrm{ng} / \mathrm{ml} \mathrm{TNF-} \alpha, 0.1$ or $1 \mathrm{ng} / \mathrm{ml}$ IL-10, or combinations of both cytokines (Peprotech). These doses were selected based on the concentrations of TNF- $\alpha$ and IL-10 in the mixtures of DMEM and CM from LPS-stimulated $M \Phi_{\mathrm{GM}}$ or $M \Phi_{\mathrm{M}}$ used for MSC treatments. MSC treated with CM or cytokines are referred to as primed MSC. The transwells with unprimed or primed MSC were washed with PBS and transferred to six-well plates containing cultures of $M \Phi_{\mathrm{GM}}$ or $\mathrm{M} \Phi_{\mathrm{M}}$ and incubated for $24 \mathrm{~h}$ in $3 \mathrm{ml}$ of a mixture of equal volumes of RPMI and DMEM containing $12.5 \%$ FBS and $10 \mathrm{ng} / \mathrm{ml}$ LPS. When indicated, $1 \mu \mathrm{g} / \mathrm{ml}$ antibody against $\mathrm{PGE}_{2}$ (Cayman Chemical Company, Ann Arbor, MI, USA) or IL-6 (R\&D Systems, Wiesbaden, Germany) was added along with LPS. At the end of the incubation period, the number of live macrophages was determined by the trypan blue dye exclusion test. The experimental scheme used for setting co-cultures is shown in Fig. 1a. In some experiments, $10^{5}$ MSC were seeded in 12-well plates and incubated with $\mathrm{CM}$ or cytokines as described above. After $48 \mathrm{~h}, \mathrm{MSC}$ were washed with PBS and further incubated for $24 \mathrm{~h}$ in fresh culture media, as shown in the experimental scheme in Fig. 4a. To assess that MSC modulate cytokine secretion of stimulated macrophages in the absence of LPS, macrophages were treated with LPS for $90 \mathrm{~min}$, washed with PBS, and then co-cultured with MSC for $5 \mathrm{~h}$ in fresh media (see experimental scheme in Additional file 1: Figure S2).

\section{Collagen gel co-cultures}

Hydrogels (HG) containing $1.5 \mathrm{mg} / \mathrm{ml}$ collagen were prepared by mixing at $4{ }^{\circ} \mathrm{C} 40 \mu \mathrm{l}$ of $10 \mathrm{X}$ DMEM, $10 \mu \mathrm{l}$ of $1 \mathrm{~N}$ $\mathrm{NaOH}, 162 \mu \mathrm{l}$ of $\mathrm{H}_{2} \mathrm{O}, 8 \mu \mathrm{l}$ of $7.5 \% \mathrm{NaHCO}_{3}, 100 \mu \mathrm{l}$ of serum-free DMEM, and $180 \mu \mathrm{l}$ of $5 \mathrm{mg} / \mathrm{ml}$ rat-tail type I collagen diluted in $0.1 \mathrm{M}$ acetic acid (Ibidi $\mathrm{GmbH}$, Martinsried, Germany). $10^{5}$ MSC, previously treated or not for $48 \mathrm{~h}$ with $\mathrm{CM}$, were resuspended in $100 \mu \mathrm{l}$ of serum-free DMEM and added to the solution. HG-lacking cells were used as controls. After homogenizing the mixture by pipetting, $600 \mu \mathrm{l}$ of suspension were distributed 
a

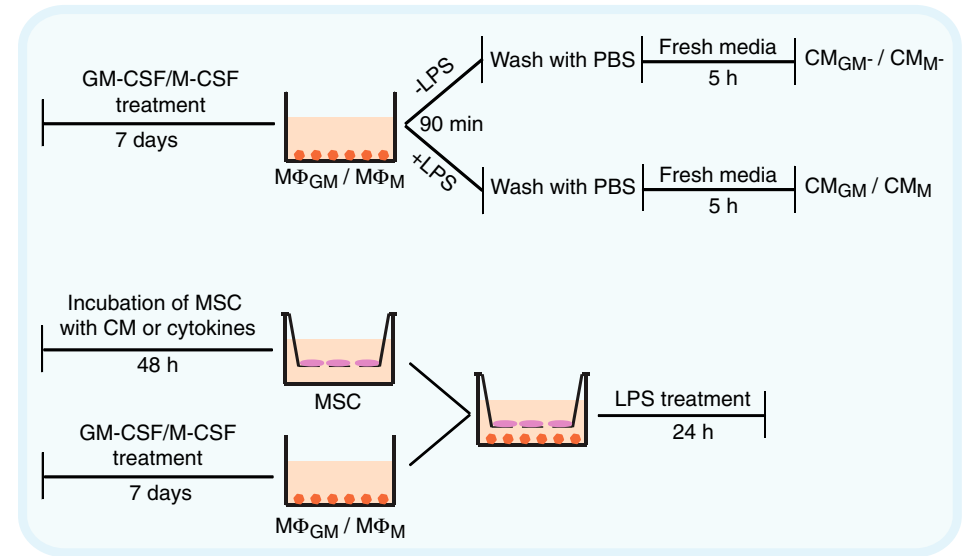

b

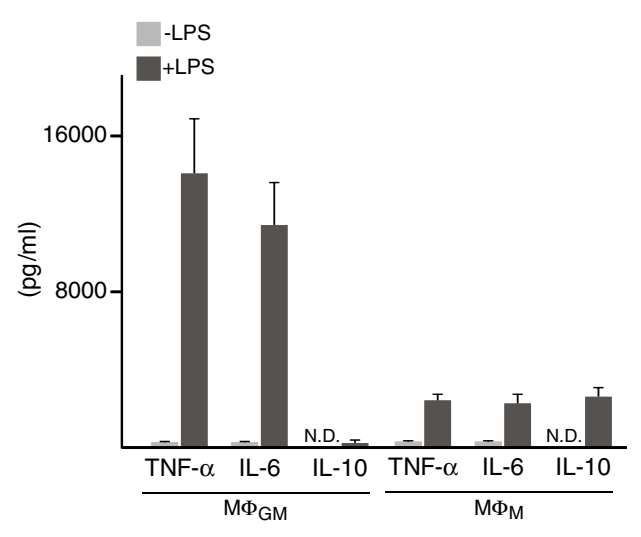

C

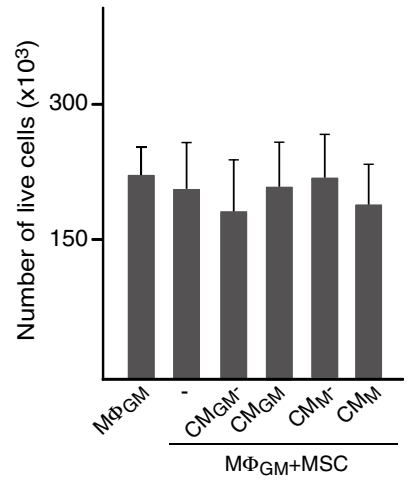

d

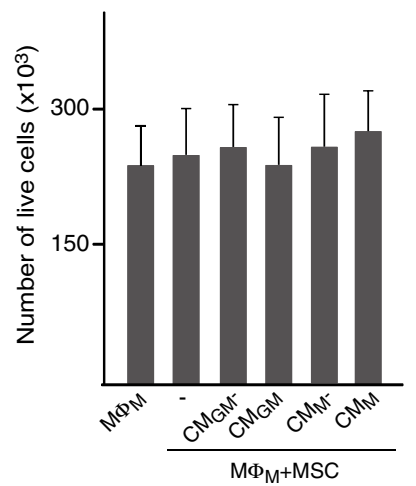

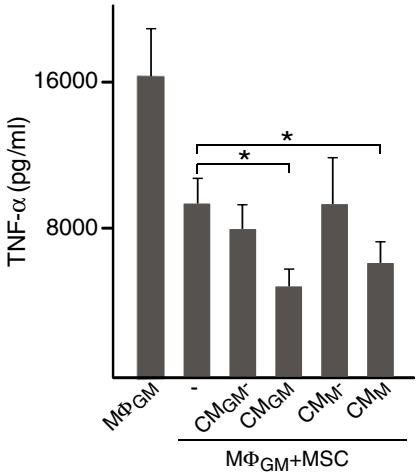
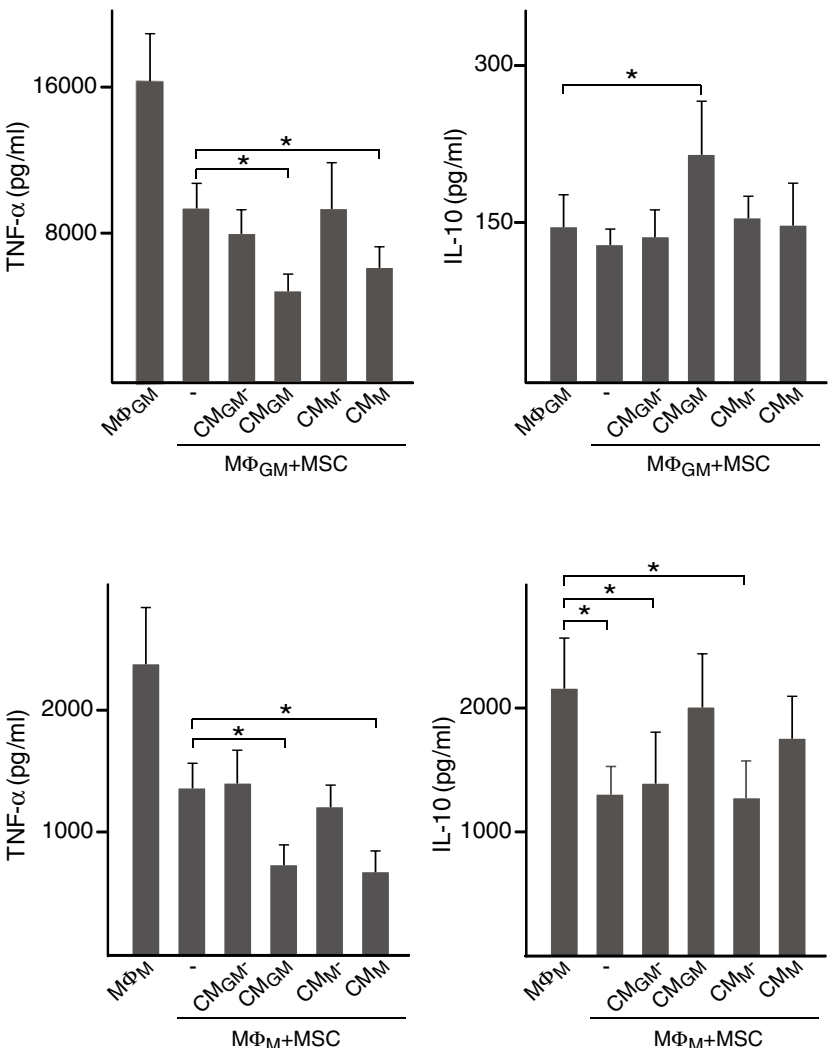

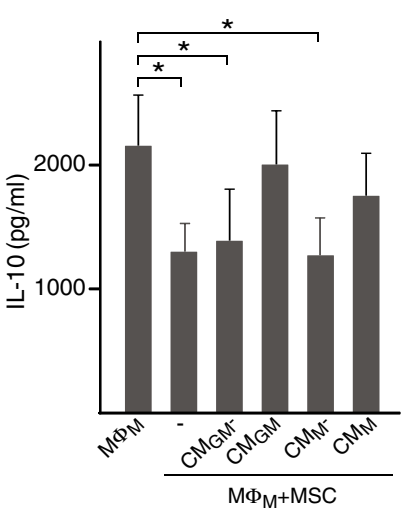

Fig. 1 Immunomodulatory effects of MSC primed with CM from macrophages. a Scheme used to generate conditioned media (CM) from macrophages (upper row). $M \Phi_{G M}$ or $M \Phi_{M}$ were treated $\left(C M_{G M}\right.$ or $C M_{M}$, respectively) or not $\left(C_{G M}-\right.$ or $C M_{M}-$, respectively) with $L P S$ for 90 min, thoroughly washed with PBS to remove LPS, and incubated in fresh media for $5 \mathrm{~h}$. Scheme of the set-up of co-cultures (lower row). MSC were incubated or not with CM from macrophages or with cytokines for $48 \mathrm{~h}$, thoroughly washed with PBS, and co-cultured with $M \Phi_{G M}$ or $M \Phi_{M}$ in the presence of LPS for $24 \mathrm{~h}$. $\mathbf{b}$ Levels of inflammatory cytokines in $C M$ of $M \Phi_{G M}$ or $M \Phi_{M}$ stimulated or not with $L P S$. Number of $M \Phi_{G M}(\mathbf{c})$ or $M \Phi_{M}(\mathbf{d})$ cultured in isolation or co-cultured with MSC primed or not (-) with CM (left graphs) and levels of TNF-a (middle graphs) and IL-10 (right graphs) in media. ${ }^{*} p<0.05$. N.D., not detected

per well of 24-well plates and incubated at $37^{\circ} \mathrm{C}$ for 30 min. After polymerization, $600 \mu \mathrm{l}$ of RPMI supplemented with $25 \%(v / v)$ FBS were added and $2 \times 10^{5} \mathrm{M} \Phi_{\mathrm{GM}}$ or
$M \Phi_{M}$ were seeded onto HG loaded or not with MSC. Then, HG media were supplemented with $10 \mathrm{ng} / \mathrm{ml}$ LPS and incubated for $24 \mathrm{~h}$. For comparative purposes, 
macrophages were seeded on 24-well plates made of tissue culture plastic (TCP) and incubated for $24 \mathrm{~h}$ in $1200 \mu \mathrm{l}$ of a mixture of equal volumes of RPMI and DMEM containing $12.5 \% \mathrm{FBS}$ and $10 \mathrm{ng} / \mathrm{ml} \mathrm{LPS}$. In the case of MSC, cells were seeded on TCP or encapsulated in HG and further incubated for $24 \mathrm{~h}$ in the same media without LPS. The experimental scheme used is shown in Fig. 8a. The cell morphology was observed under a phase-contrast microscope (Nikon Diaphot, Tokio, Japan).

\section{Flow cytometry assays}

Immunofluorescence staining of cell surface antigens in MSC was performed by incubating cells for $30 \mathrm{~min}$ at $4{ }^{\circ} \mathrm{C}$ in the dark with mouse anti-human leukocyte antigen (HLA)-DR, DP, DQ (HLA class II)-FITC, HLA-ABC (HLA class I)-APC, CD34-FITC, CD44-FITC, CD105-PE, CD29-APC, and CD45-APC Abs (all from BD Biosciences, San Jose, CA,USA). Phenotypic characterization of macrophages generated by incubation with GM-CSF or M-CSF was assessed by staining with CD163-PE, CD197 (CCR7)-FITC, and CD80-APC (all from Miltenyi Biotec, Bergisch-Gladbach, Germany). Cells incubated in the absence of antibodies were used as controls. After incubation, cells were washed three times with PBS, fixed with $1 \%(w / v)$ formaldehyde in PBS, and analyzed by flow cytometry using a FACSCalibur analyzer and CellQuest software (both from BD Biosciences).

\section{Immunoenzymatic assays}

The culture media were clarified by centrifugation at $1200 \mathrm{~g}$ for $10 \mathrm{~min}$; supplemented with $2 \mu \mathrm{g} / \mathrm{ml}$ aprotinin, $17.5 \mu \mathrm{g} / \mathrm{ml}$ phenyl-methylsulfonyl fluoride, $1 \mu \mathrm{g} / \mathrm{ml}$ pepstatin A, and $50 \mu \mathrm{g} / \mathrm{ml}$ bacitracin (Sigma); and stored at $-80^{\circ} \mathrm{C}$. Levels of TNF- $\alpha$, IL-10, and IL- 6 in cell culture media were determined using BD CBA Flex Sets (BD Biosciences). The data were acquired using a FACSCalibur flow cytometer and analyzed with the FCAP Array Software version 3.0 (BD Biosciences). The detection limits of the CBA Flex Sets were $3.7 \mathrm{pg} / \mathrm{ml}$ for TNF- $\alpha$, $2.5 \mathrm{pg} / \mathrm{ml}$ for IL-6, and $3.3 \mathrm{pg} / \mathrm{ml}$ for IL-10. PGE 2 levels were measured using a human-specific ELISA kit (Cayman) with a detection limit of $15 \mathrm{pg} / \mathrm{ml}$.

\section{Gene expression}

Total RNA was isolated using TRI Reagent (Molecular Research Center, Inc., Cincinnati, OH, USA). Complementary DNAs were prepared from total RNA using the Transcriptor Reverse Transcriptase and an anchored-oligo $(\mathrm{dT})_{18}$ primer (Roche Applied Science, Indianapolis, IN, USA). Real-time quantitative PCR was performed using LightCycler FastStart DNA Master SYBR Green I and LightCycler detector (Roche). Quantitative expression values were extrapolated from standard curves and were normalized to glyceraldehyde 3-phosphate dehydrogenase
(GAPDH) values. Specific oligonucleotide primers were IL-6, 5' -CCCCAGGAGAAGATTCCAAA-3' (forward primer, F), 5'-CCAGTGATGATTTTCACCAGG-3' (reverse primer, R); cyclooxygenase-2 (COX-2), 5'-TGAGCATCT ACGGTTTGCTG-3' (F), 5'-TGCTTGTCTGGAACAAC TGC-3' (R); and GAPDH, 5' -GTGAAGGTCGGAGTCAA CG-3' (F), 5' -GAAGATGGTGATGGGATTTCC-3' (R).

\section{Statistical analysis}

The statistical analyses were performed using the Statistical Program for Social Sciences version 11.5 (SPSS Inc., Chicago, IL, USA). Data are presented as means \pm SD of six independent experiments. Quantitative data were tested using two-sided Kruskal-Wallis and Mann-Whitney $U$ rank-sum tests. Post hoc comparisons were analyzed by the Mann-Whitney $U$ test, adjusting the $p$ value with the Bonferroni correction, and the level of significance was set to $p<0.05$.

\section{Results \\ Priming MSC with factors secreted by pro-inflammatory or anti-inflammatory macrophages enhances their immunomodulatory potential}

We primed MSC with CM from $M \Phi_{\mathrm{GM}}$ or $M \Phi_{\mathrm{M}}$ stimulated or not with LPS to examine the influence of inflammatory cytokines on MSC immunomodulatory potential (Fig. 1a). $M \Phi_{\mathrm{GM}}$ expressed the $\mathrm{M} 1$ markers CD80 and CCR7 whereas they were devoid of cell surface CD163, a marker of $M 2$ macrophages. In contrast, $M \Phi_{M}$ expressed high levels of CD163 and very low levels of CD80 and CCR7 (Additional file 1: Figure S1). The concentrations of inflammatory cytokines in the CM from $\mathrm{M} \Phi_{\mathrm{GM}}$ or $\mathrm{M} \Phi_{\mathrm{M}}$ correlated with their pro-inflammatory or anti-inflammatory phenotype, respectively (Fig. 1b). $\mathrm{CM}$ from LPS-stimulated $\mathrm{M} \Phi_{\mathrm{GM}}\left(\mathrm{CM}_{\mathrm{GM}}\right)$ contained higher levels of TNF- $\alpha$ and IL-6 and lower levels of IL-10 than CM from LPS-stimulated $M \Phi_{M}\left(C_{M}\right)$. IL-10 levels could not be detected in CM from unstimulated macrophages, which contained low concentrations of TNF- $\alpha$ and IL-6 (Fig. 1b). To evaluate their immunomodulatory potential, MSC primed or not with $\mathrm{CM}$ were co-cultured with $M \Phi_{\mathrm{GM}}$ or $M \Phi_{\mathrm{M}}$ as shown in Fig. 1a. MSC did not affect macrophage viability, as numbers of live $M \Phi_{\mathrm{GM}}$ or $M \Phi_{M}$ cultured in isolation or co-cultured with primed or unprimed MSC were similar (Fig. 1c, d, left panels). Co-culture of $M \Phi_{\mathrm{GM}}$ with unprimed MSC decreased TNF- $\alpha$ levels, an effect also observed in co-cultures of $M \Phi_{M}$ (Fig. 1c, d, middle panels). MSC primed with $\mathrm{CM}$ from unstimulated macrophages had no effect on TNF- $\alpha$ secretion from $M \Phi_{\mathrm{GM}}$ or $M \Phi_{\mathrm{M}}$ (Fig. 1c, d, middle panels). However, MSC primed with CM from LPS-stimulated macrophages further decreased TNF- $\alpha$ levels in co-cultures and no differences were found between priming with $\mathrm{CM}_{\mathrm{GM}}$ or $\mathrm{CM}_{\mathrm{M}}$ (Fig. 1c, $\mathrm{d}$, middle panels). The 
low IL-10 levels secreted by $\mathrm{M} \Phi_{\mathrm{GM}}$ were not altered when co-cultured with unprimed MSC or $\mathrm{CM}_{\mathrm{M}}$-primed MSC but increased in co-cultures with $\mathrm{CM}_{\mathrm{GM}}$-primed $\mathrm{MSC}$ (Fig. 1c, right panels). IL-10 production by $M \Phi_{M}$ was notably reduced in co-cultures with unprimed MSC (Fig. 1d, right panels). However, this reduction was not observed when MSC were primed with $\mathrm{CM}_{\mathrm{GM}}$ or $\mathrm{CM}_{\mathrm{M}}$. As observed for TNF- $\alpha$, IL-10 levels in co-cultures were unaffected by priming MSC with CM from unstimulated macrophages (Fig. 1c, d, right panels). To assess that MSC can modulate TNF- $\alpha$ and IL-10 secretion of stimulated macrophages in the absence of LPS, macrophages were treated with LPS, washed, and then co-cultured with MSC in fresh media (Additional file 1: Figure S2). Under these conditions, MSC decreased TNF- $\alpha$ levels in co-cultures with $\mathrm{M} \Phi_{\mathrm{GM}}$ or $\mathrm{M} \Phi_{\mathrm{M}}$ and priming MSC with $\mathrm{CM}_{\mathrm{GM}}$ or $\mathrm{CM}_{\mathrm{M}}$ increased their immunomodulatory properties, as observed in co-cultures treated with LPS. Also, changes in IL-10 levels induced by MSC were similar in co-cultures with or without LPS. Taken together, our data show that MSC primed with CM from LPS-stimulated macrophages, which contain high levels of inflammatory mediators, display greater immunomodulatory potential than unprimed MSC.

\section{TNF- $a$ and IL-10 in CM from macrophages are involved in} priming MSC

We next investigated the role of the pro-inflammatory TNF- $\alpha$ and the anti-inflammatory IL-10 cytokines as priming factors for MSC. For this purpose, CM from macrophages were incubated with neutralizing TNF- $\alpha$ or IL-10 antibody before being added to MSC. Treatment of $\mathrm{CM}_{\mathrm{GM}}$ or $\mathrm{CM}_{\mathrm{M}}$ with anti-TNF- $\alpha$ reduced the ability of primed MSC to decrease TNF- $\alpha$ levels in co-cultures of $M \Phi_{\mathrm{GM}}$ (Fig. 2a, left panel). Interestingly, a modulatory effect on TNF- $\alpha$ secretion was also observed when $\mathrm{CM}_{\mathrm{M}}$, which contained high IL-10 amounts, were treated with anti-IL-10. IL-10 secretion induced by $\mathrm{CM}_{\mathrm{GM}}$-primed MSC in co-cultures of $\mathrm{M} \Phi_{\mathrm{GM}}$ was attenuated when $C M$ were incubated with anti-TNF- $\alpha$ (Fig. 2a, right panel). Neutralization of IL-10 in $\mathrm{CM}_{\mathrm{GM}}$ had no effect on TNF- $\alpha$ and IL-10 levels (Fig. 2a). To further investigate the effect of TNF- $\alpha$ and IL-10 on MSC, cells were incubated with these cytokines before co-culturing

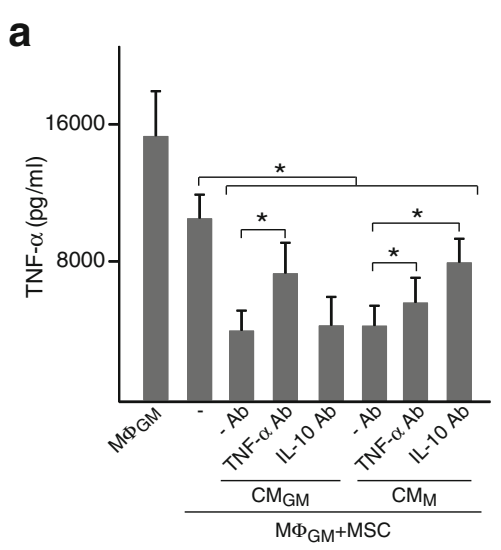

b

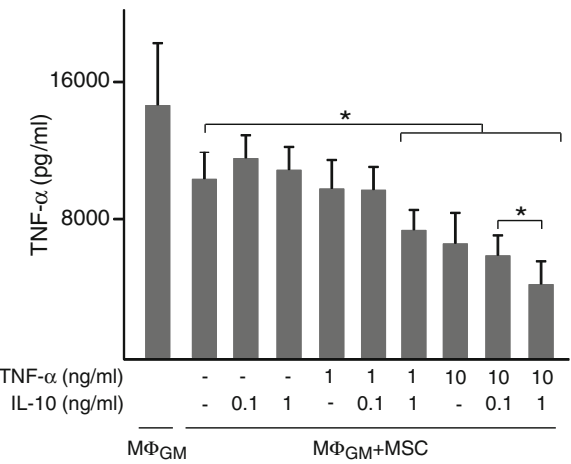

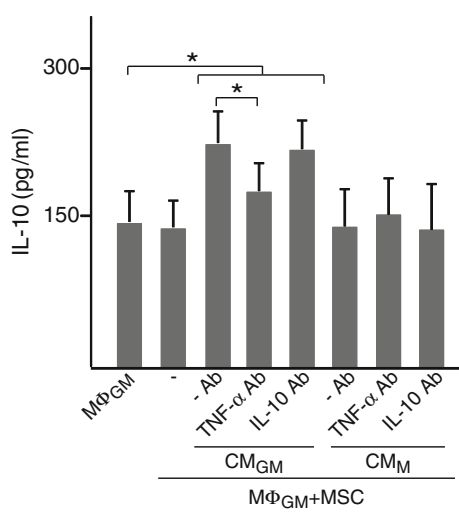

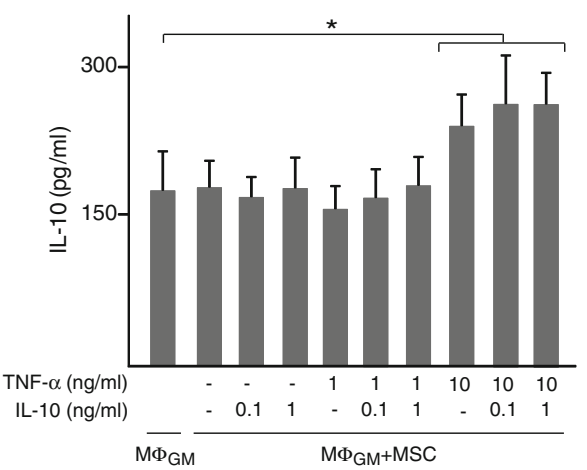

Fig. 2 TNF- $a$ and IL-10 prime MSC to regulate cytokine secretion from pro-inflammatory macrophages. a TNF-a and IL-10 levels in media of M $\Phi_{G M}$ cultured in isolation or co-cultured with MSC primed or not (-) with $\mathrm{CM}_{\mathrm{GM}}$ or $\mathrm{CM}_{\mathrm{M}}$. CM were incubated or not (-Ab) with neutralizing antibody (Ab) against TNF-a or IL-10. $\mathbf{b}$ TNF-a and IL-10 levels in media of $M \Phi_{G M}$ cultured in isolation or co-cultured with MSC primed or not (-) with the indicated doses of TNF-a, IL-10 or combinations of both cytokines. ${ }^{*} p<0.05$ 
with $M \Phi_{\mathrm{GM}}$ (Fig. 2b). IL-10 at $0.1 \mathrm{ng} / \mathrm{ml}$ had no effect on MSC immunomodulation. TNF- $\alpha$ levels in cocultures were also unaffected by priming MSC with either IL-10 or TNF- $\alpha$ at $1 \mathrm{ng} / \mathrm{ml}$, but decreased after incubation with both cytokines (Fig. 2b, left panel). Priming MSC with $10 \mathrm{ng} / \mathrm{ml}$ TNF- $\alpha$ diminished TNF- $\alpha$ levels in co-cultures, which further decreased when MSC were primed with $10 \mathrm{ng} / \mathrm{ml}$ TNF- $\alpha$ plus $1 \mathrm{ng} / \mathrm{ml}$ IL-10. Finally, IL-10 levels in co-cultures increased only when MSC were primed with $10 \mathrm{ng} / \mathrm{ml}$ TNF- $\alpha$, alone or in combination with IL-10 (Fig. 2b, right panel). Regarding co-cultures of $M \Phi_{M}$, neutralization of TNF- $\alpha$ in $\mathrm{CM}_{\mathrm{GM}}$ or $\mathrm{CM}_{\mathrm{M}}$ reduced the ability of primed MSC to modulate TNF- $\alpha$ levels without affecting IL-10 (Fig. 3a). Moreover, blocking IL-10 in $\mathrm{CM}_{\mathrm{M}}$ suppressed the regulatory effects of primed MSC. Priming effects of TNF- $\alpha$ on MSC in co-cultures of $M \Phi_{M}$ increased when $1 \mathrm{ng} / \mathrm{ml}$ IL-10 was added (Fig. 3b, left panel). Notably, IL-10 levels increased when $M \Phi_{M}$ were co-cultured with MSC primed with $1 \mathrm{ng} / \mathrm{ml}$ of IL-10 independently of the presence of TNF- $\alpha$ (Fig. 3b, right panel). Overall, these data indicate that TNF- $\alpha$ and IL-10 secreted from macrophages prime MSC to enhance their immunomodulatory potential.

\section{Immunomodulatory effects of primed MSC on macrophages are mediated by $\mathrm{PGE}_{2}$}

Next, we examined whether the soluble mediators $\mathrm{PGE}_{2}$ and IL- 6 are involved in the immunomodulation mediated by primed MSC. Priming MSC with CM resulted in increased secretion of IL-6, which reached higher levels after incubation with $\mathrm{CM}_{\mathrm{GM}}$ than with $\mathrm{CM}_{\mathrm{M}}$ (Fig. 4b, left panel). To explore whether TNF- $\alpha$ and IL-10 originated from macrophages play a role in this regulation, $\mathrm{CM}$ were incubated with neutralizing antibodies. The increase in IL- 6 secretion induced by $\mathrm{CM}_{\mathrm{GM}}$ or $\mathrm{CM}_{\mathrm{M}}$ was attenuated by blocking TNF- $\alpha$ but not IL-10. Interestingly, $\mathrm{PGE}_{2}$ production increased to a similar extent in MSC primed with $\mathrm{CM}_{\mathrm{GM}}$ or $\mathrm{CM}_{\mathrm{M}}$ and this effect was largely attenuated by neutralizing TNF- $\alpha$ (Fig. $4 \mathrm{~b}$, right panel). Blocking IL-10 decreased $\mathrm{PGE}_{2}$ levels secreted by MSC primed with $\mathrm{CM}_{\mathrm{M}}$ but not with $\mathrm{CM}_{\mathrm{GM}}$. Incubation of MSC with TNF- $\alpha$ but not IL-10 induced a dose-dependent increase in IL-6 and $\mathrm{PGE}_{2}$ secretion
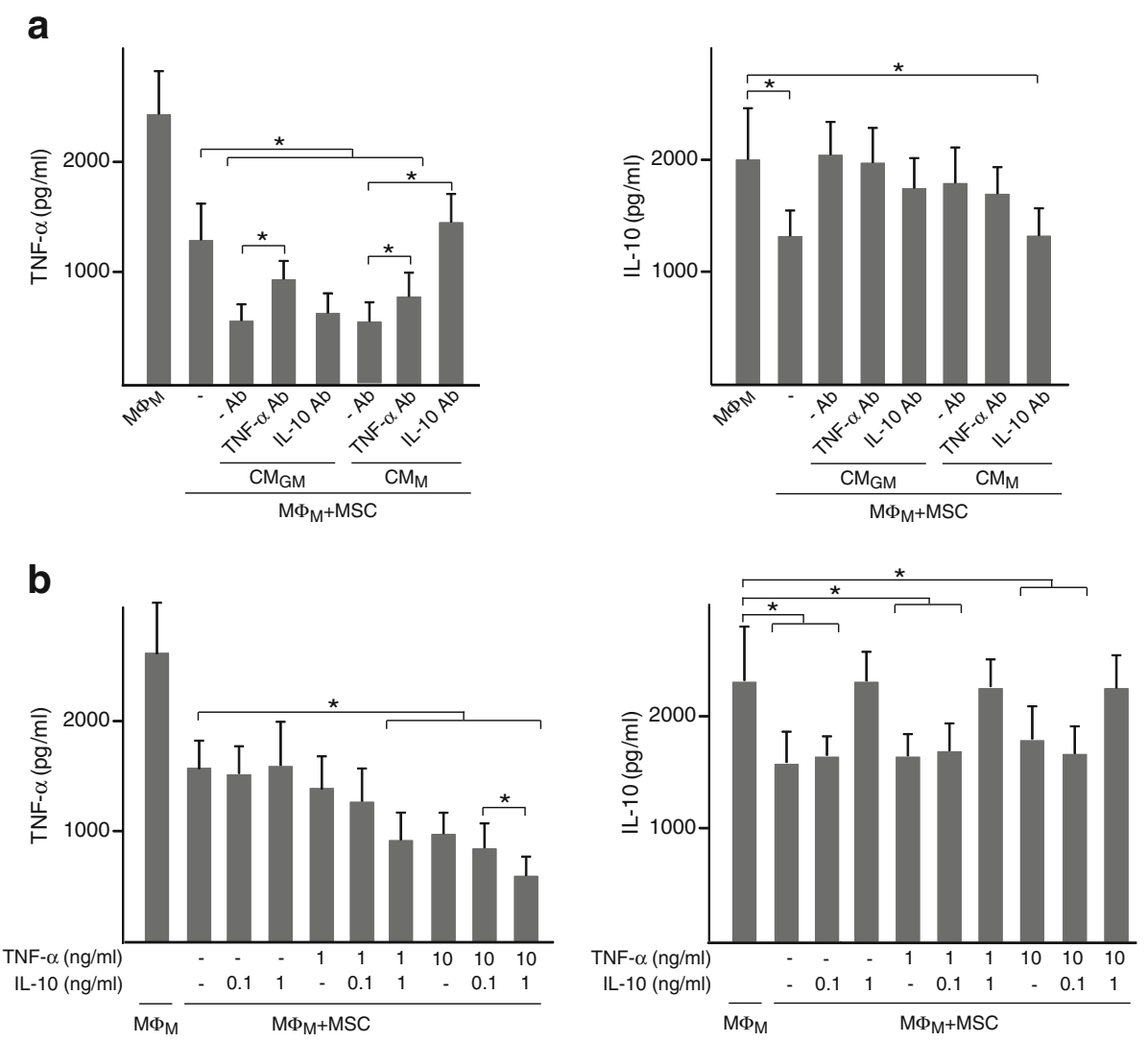

Fig. 3 TNF- $a$ and IL-10 prime MSC to regulate cytokine secretion from anti-inflammatory macrophages. a TNF- $a$ and IL-10 levels in media of M $\Phi_{M}$ cultured in isolation or co-cultured with MSC primed or not (-) with $\mathrm{CM}_{\mathrm{GM}}$ or $\mathrm{CM}_{\mathrm{M}}$. $\mathrm{CM}$ were incubated or not (-Ab) with neutralizing antibody (Ab) against TNF-a or IL-10. b TNF- $a$ and IL-10 levels in media of MФ $\Phi_{M}$ cultured in isolation or co-cultured with MSC primed or not (-) with the indicated doses of TNF-a, IL-10 or combinations of both cytokines. ${ }^{*} p<0.05$ 


\section{a}

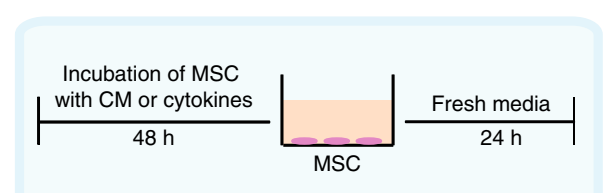

b
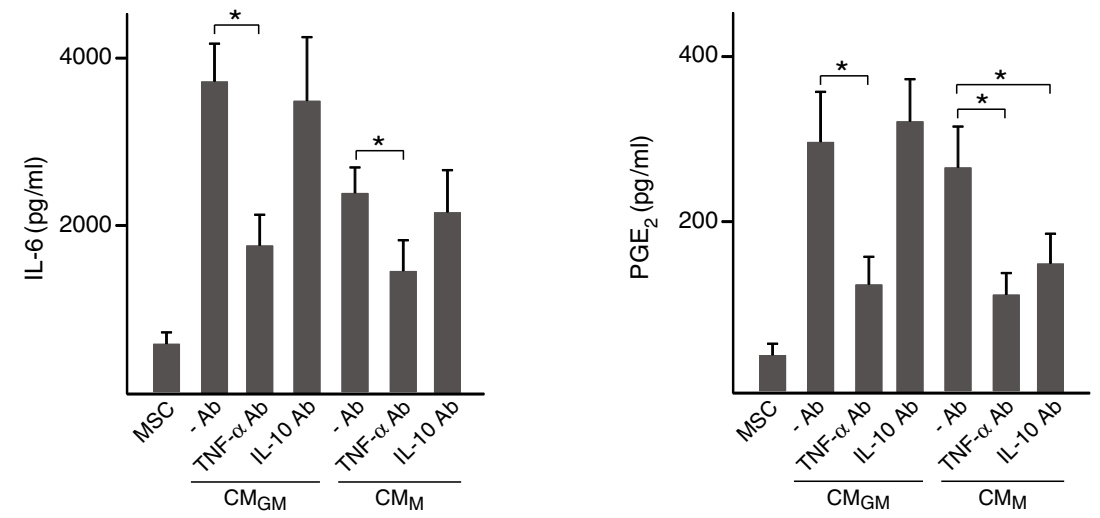

C
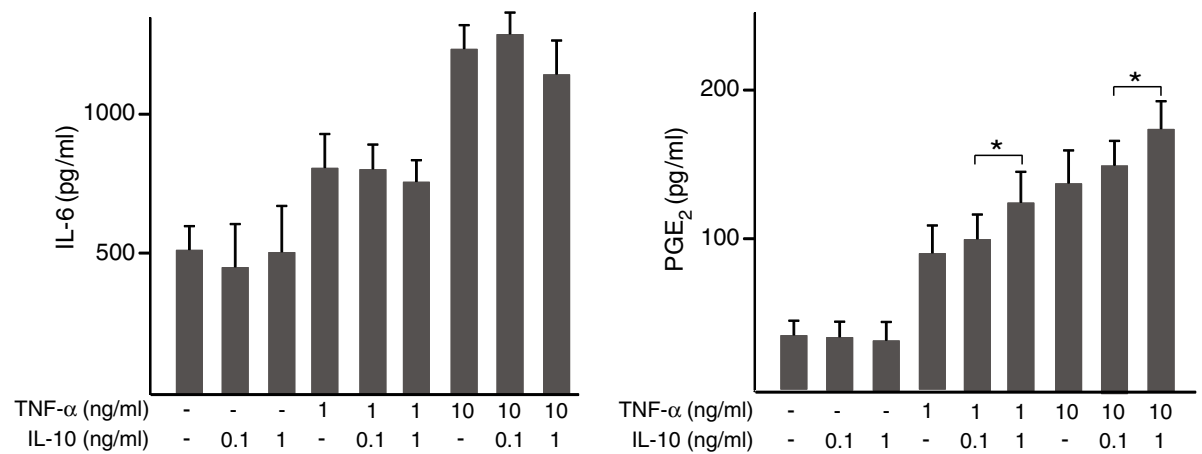

Fig. $4 \mathrm{IL}-6$ and $\mathrm{PGE}_{2}$ secretion by primed MSC. a Scheme of MSC treatment with CM or cytokines. b IL-6 and PGE 2 levels in media of MSC primed or not (-) with $\mathrm{CM}_{\mathrm{GM}}$ or $\mathrm{CM}_{\mathrm{M}}$. CM were incubated or not (-Ab) with neutralizing antibody (Ab) against TNF-a or IL-10. $\mathbf{c} I L-6$ and PGE 2 levels in media of MSC primed or not with the indicated doses of TNF-a, IL-10 or combinations of both cytokines. ${ }^{*} p<0.05$

(Fig. 4c). Notably, MSC primed with TNF- $\alpha$ in combination with high doses of IL-10 secreted higher $\mathrm{PGE}_{2}$ levels than MSC treated with TNF- $\alpha$ alone (Fig. 4c, right panel). This effect was not observed for IL-6 secretion (Fig. 4c, left panel). IL-6 levels were substantially higher in single-cultured $M \Phi_{\mathrm{GM}}$ than in $M \Phi_{\mathrm{M}}$ whereas $\mathrm{PGE}_{2}$ secretion was similar for both macrophage phenotypes (Fig. 5a). Co-culturing with primed or unprimed MSC led to a similar increase in IL-6 levels (Fig. 5a, left panel). PGE ${ }_{2}$ levels also increased upon co-culturing $M \Phi_{\mathrm{GM}}$ or $M \Phi_{\mathrm{M}}$ with MSC although increased further when MSC were primed with $\mathrm{CM}$ (Fig. 5a, right panel). No differences were found between priming with $\mathrm{CM}_{\mathrm{GM}}$ or $\mathrm{CM}_{\mathrm{M}}$. Next, mRNA levels of IL6 and COX2, a key enzyme in $\mathrm{PGE}_{2}$ synthesis, were determined in MSC cultured in isolation or co-cultured with macrophages. IL6 and COX2 mRNA levels in single-cultured MSC correlated with IL-6 and $\mathrm{PGE}_{2}$ secretion profiles (Figs. $5 \mathrm{~b}$ and $4 \mathrm{~b}$ ). IL6 mRNA levels increased after priming MSC with CM, but to a higher extent with $\mathrm{CM}_{\mathrm{GM}}$ than with $\mathrm{CM}_{\mathrm{M}}$. In contrast, COX2 transcript levels increased to the same extent after exposure to $\mathrm{CM}_{\mathrm{GM}}$ or $\mathrm{CM}_{\mathrm{M}}$ (Fig. 5b). IL6 and COX2 mRNA levels in MSC substantially increased when co-cultured with macrophages. Similar to that observed at the secretion level, COX2 mRNA levels in primed MSC co-cultured with macrophages were higher than those in unprimed counterparts whereas these differences were not found in IL6 transcript (Fig. 5b). These results indicate that priming with $\mathrm{CM}$ may potentiate the secretion of $\mathrm{PGE}_{2}$ from MSC in co-cultures but not of IL-6. 

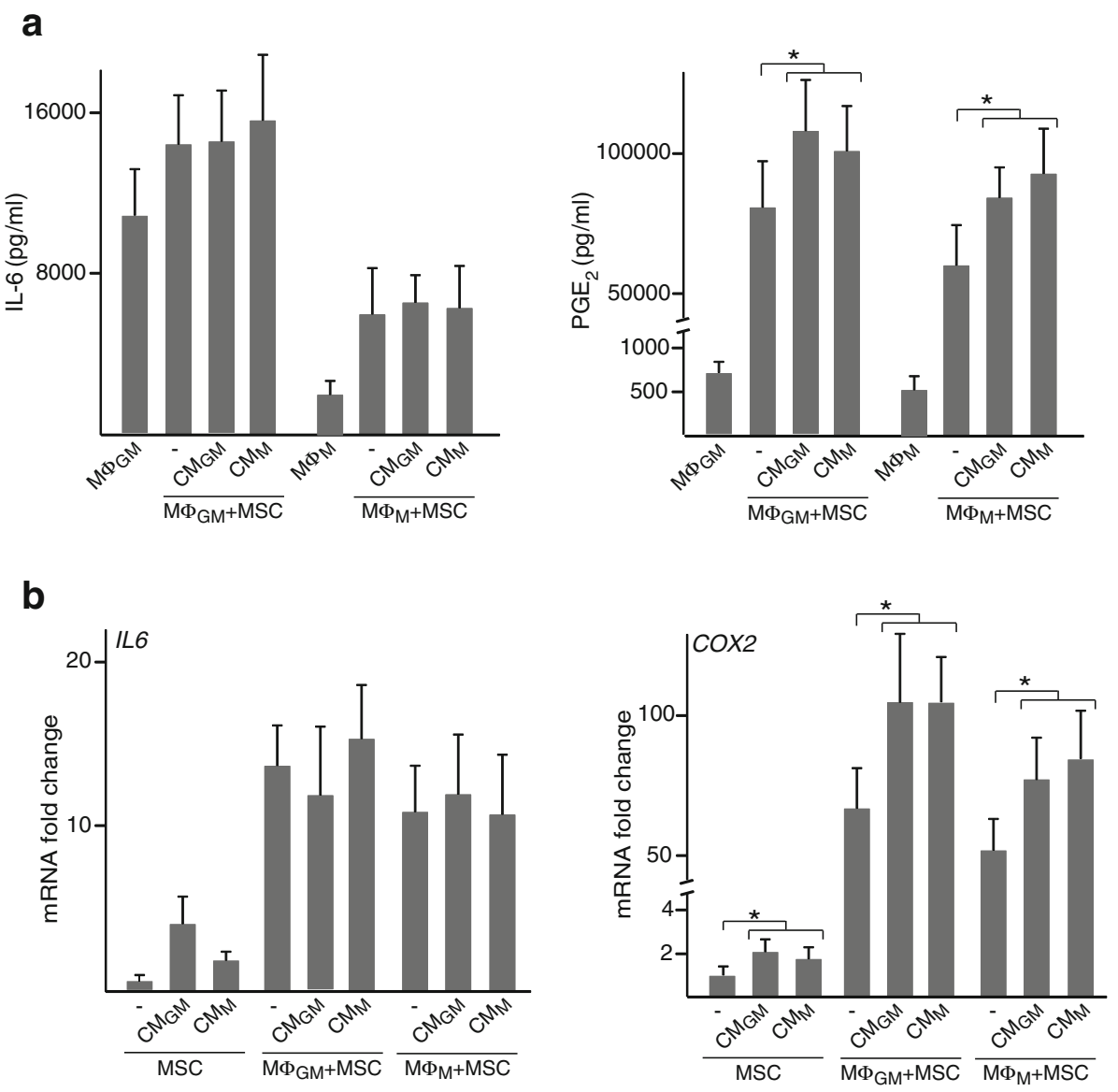

Fig. $5 \mathrm{IL}-6$ and $\mathrm{PGE} 2$ secretion and mRNA levels in co-cultures of macrophages and primed MSC. a IL-6 and PGE levels in media of M $\Phi_{G M}$ or $M \Phi_{M}$ cultured in isolation or co-cultured with MSC primed or not (-) with $C M_{G M}$ or $C M_{M} \cdot \mathbf{b} / L 6$ and COX2 mRNA fold changes in MSC primed or not with $C M$ and cultured in isolation or co-cultured with $M \Phi_{G M}$ or $M \Phi_{M}$. mRNA data are relative to those measured in unprimed MSC cultured in isolation, which were given the arbitrary value of $1 .{ }^{*} p<0.05$

To examine whether TNF- $\alpha$ and IL-10 secretion from macrophages was regulated by $\mathrm{PGE}_{2}$ and IL-6, co-cultures were incubated with neutralizing antibodies against these mediators. TNF- $\alpha$ levels were similar in co-cultures incubated with anti- $\mathrm{PGE}_{2}$ and in macrophages cultured in isolation (Fig. 6a, b, left panels). In contrast, TNF- $\alpha$ levels in co-cultures treated with anti-IL-6 were lower than in isolated macrophages. The regulation in TNF- $\alpha$ levels induced by MSC primed with $\mathrm{CM}_{\mathrm{GM}}$ or $\mathrm{CM}_{\mathrm{M}}$ was suppressed by blocking PGE $_{2}$ but not IL-6 (Fig. 6a, b, left panels). IL-10 levels in co-cultures were hardly affected by incubation with neutralizing antibodies. The only effect was observed in co-cultures of $M \Phi_{\mathrm{GM}}$ as the increase in IL-10 levels induced by $\mathrm{CM}_{\mathrm{GM}}$-primed MSC was attenuated when $\mathrm{PGE}_{2}$ was blocked (Fig. 6a, right panel). These data show that primed MSC co-cultured with macrophages decrease TNF- $\alpha$ levels through the secretion of $\mathrm{PGE}_{2} . \mathrm{PGE}_{2}$ is also involved in the regulation of IL-10 in co-cultures of primed MSC with $M \Phi_{\mathrm{GM}}$ but not with $M \Phi_{M}$.
Primed MSC encapsulated in collagen hydrogels promote macrophage anti-inflammatory versus pro-inflammatory cytokine secretion

Immune rejection of allogeneic MSC has been associated with an alteration in HLA expression following exposure to inflammatory factors $[20,21]$. Cell surface levels of HLA class I increased after treatment of MSC with CM, while no effect was observed for HLA class II (Fig. 7). Expression levels of other cell surface molecules related to MSC identity were not altered by CM treatment (Fig. 7). Encapsulation of MSC in HG has been proposed as a strategy to enhance their survival after transplantation and potentiate their function. We extended our study to explore the immunomodulatory properties of CM-primed MSC encapsulated in collagen HG, where cells are permitted to grow in three dimensions. To this end, $M \Phi_{\mathrm{GM}}$ or $M \Phi_{\mathrm{M}}$ were seeded on HG, loaded or not with MSC, and stimulated with LPS. Macrophages or MSC were also cultured on TCP, as classical 2D cell growth conditions (Fig. 8a). On TCP, most $\mathrm{M} \Phi_{\mathrm{GM}}$ 

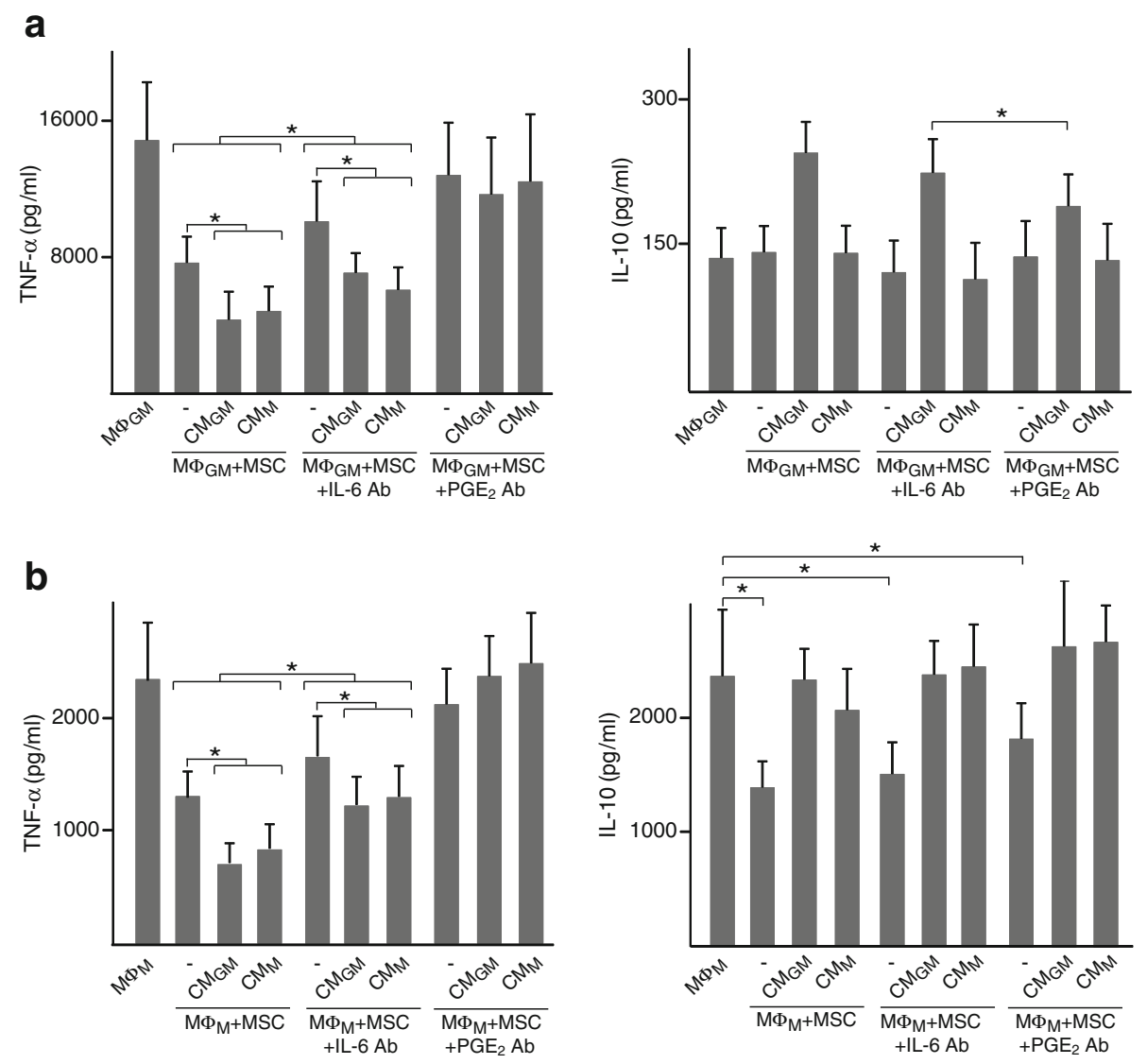

Fig. 6 Involvement of IL-6 and PGE $E_{2}$ in the regulation of macrophage cytokine secretion by primed MSC. TNF-a and IL-10 levels in media of M $\Phi_{G M}(\mathbf{a})$ or $M \Phi_{M}(\mathbf{b})$ cultured in isolation or co-cultured with MSC primed or not (-) with $\mathrm{CM}_{\mathrm{GM}}$ or $\mathrm{CM}_{M}$. Co-cultures were incubated in the absence or presence of neutralizing antibody (Ab) against IL-6 or PGE ${ }^{*} p<0.05$

acquired a polygonal morphology whereas the majority of $M \Phi_{M}$ exhibited an elongated spindle-like shape (Fig. 8b). However, both $M \Phi_{\mathrm{GM}}$ and $M \Phi_{\mathrm{M}}$ adopted a rounded shape when seeded on HG, being this morphological change more evident for $\mathrm{M} \Phi_{\mathrm{GM}}$. MSC encapsulated in HG were more spindle shaped than cells cultured on TCP (Fig. 8b). We found that the balance between IL-10 and TNF- $\alpha$ levels secreted from $M \Phi_{\mathrm{GM}}$ or $M \Phi_{M}$ on HG suffered important alterations compared with TCP and was characterized by higher IL-10 to TNF- $\alpha$ ratio (Fig. $8 \mathrm{c}$ ). $\mathrm{PGE}_{2}$ secretion from unprimed or primed MSC loaded in HG was higher than on TCP (Fig. 8d). As observed on TCP, priming with $\mathrm{CM}$ substantially increased $\mathrm{PGE}_{2}$ secretion from MSC in $\mathrm{HG}$ (Fig. 8d). This increase was also detected when $M \Phi_{\mathrm{GM}}$ or $M \Phi_{M}$ were co-cultured on the HG surface (Fig. 8e, f, left panels). Incubation of MSC with CM before encapsulation in HG enhanced their immunomodulatory properties on macrophages. Thus, $\mathrm{M} \Phi_{\mathrm{GM}}$ or $\mathrm{M} \Phi_{\mathrm{M}}$ cultured on MSC-loaded HG secreted lower TNF- $\alpha$ levels than macrophages cultured on empty HG, an effect further enhanced when MSC were primed with CM (Fig. 8e, f, middle panels). Interestingly, IL-10 secretion from $M \Phi_{\mathrm{GM}}$ increased when $\mathrm{HG}$ were loaded with MSC and further increased when MSC were primed with CM (Fig. 8e, right panels). High IL-10 levels secreted by $M \Phi_{M}$ on $\mathrm{HG}$ were unaffected by loading unprimed MSC whereas increased when MSC were primed with CM (Fig. 8f, right panels). In all cases, similar effects were observed by priming MSC with $\mathrm{CM}_{\mathrm{GM}}$ or $\mathrm{CM}_{\mathrm{M}}$. Taken together, these data indicate that MSC encapsulated in HG enhance the ratio of IL-10 to TNF- $\alpha$ levels secreted by $M \Phi_{\mathrm{GM}}$ or $\mathrm{M} \Phi_{\mathrm{M}}$ and that these immunoregulatory effects are potentiated by priming MSC with factors secreted by macrophages.

\section{Discussion}

Immunomodulatory effects of MSC are the result of an integrated response to extracellular stimuli, which change during the course of wound healing. MSC require threshold levels of inflammatory factors to activate their immunosuppressive function whereas insufficient MSC activation may contribute to potentiate inflammation $[10,12]$. Based on these observations, treatment of 


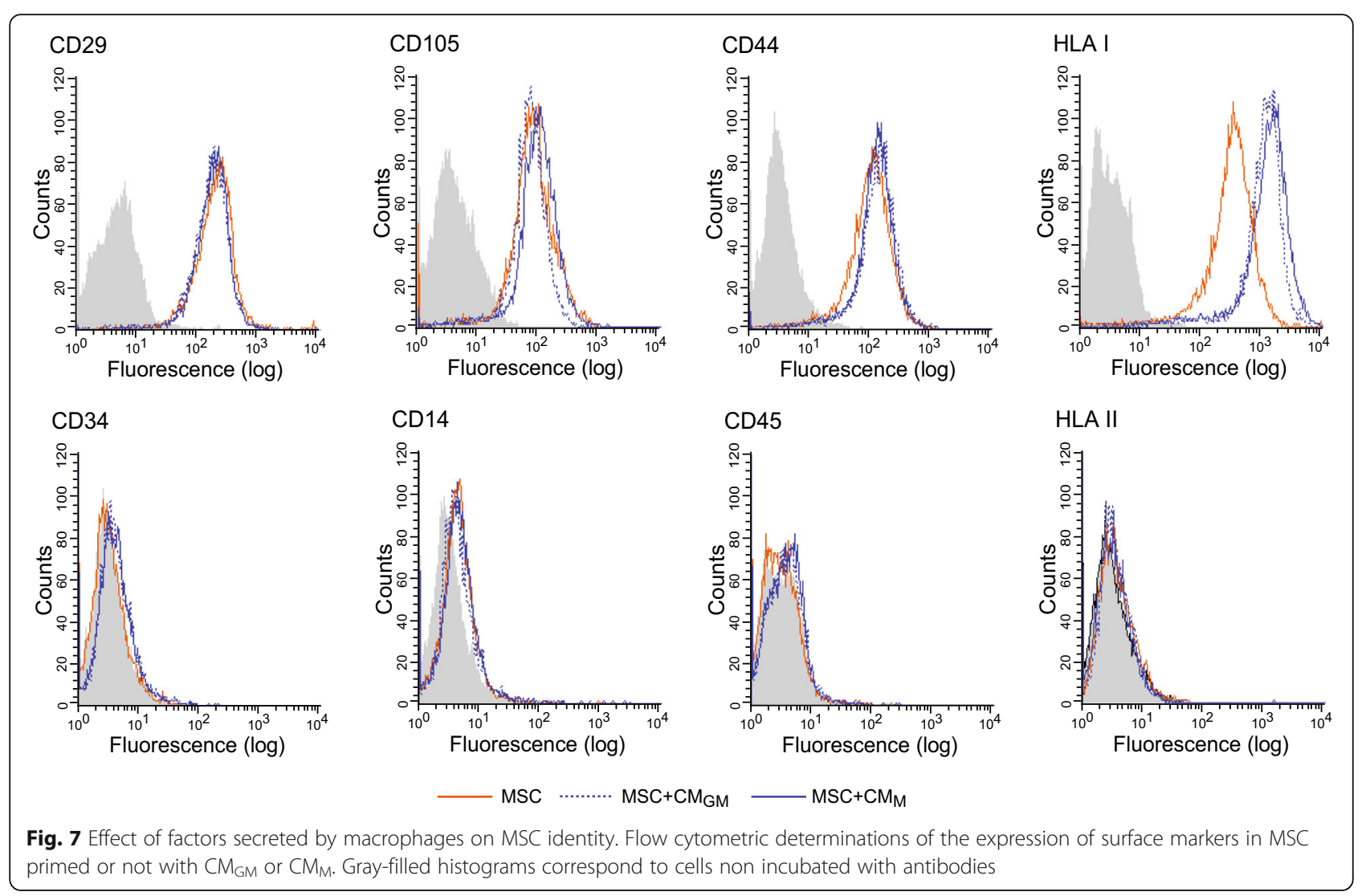

MSC with inflammatory factors prior to implantation has emerged as an attractive strategy to boost their immunoregulatory effects, as shown in animal models of colitis, acute myocardial ischemia, GvHD, and tendon and ligament healing [22-26]. Classical pro-inflammatory cytokines released at the early stage of inflammation such as IFN- $\gamma$, TNF- $\alpha$, or IL- $1 \beta$ potentiate paracrine effects of MSC on macrophages [23, 27-29]. In this work, we show for the first time that factors originated from pro-inflammatory or anti-inflammatory macrophages enhance immunomodulatory properties of MSC. Our data show that MSC immunomodulation was enhanced by priming MSC with CM from LPS-stimulated $M \Phi_{\mathrm{GM}}$ or $M \Phi_{M}$ but not by $C M$ from unstimulated macrophages, supporting the notion that MSC are mainly activated by inflammatory factors. Priming MSC with $\mathrm{CM}_{\mathrm{GM}}$ promoted $M \Phi_{\mathrm{GM}}$ polarization toward an anti-inflammatory phenotype, as evidenced by reduced TNF- $\alpha$ levels and increased IL-10 secretion. Blocking TNF- $\alpha$ in $\mathrm{CM}_{\mathrm{GM}}$ significantly attenuated the immunomodulatory effects of primed MSC indicating that TNF- $\alpha$ acts as a priming factor for MSC and therefore plays a critical role in MSC and macrophage interactions. Interestingly, MSC primed with $\mathrm{CM}_{\mathrm{M}}$ reduced TNF- $\alpha$ secretion from $\mathrm{M} \Phi_{\mathrm{GM}}$ to a similar extent than MSC primed with $\mathrm{CM}_{\mathrm{GM}}$, suggesting that MSC can be activated by the cytokine milieu of damaged and repairing tissue. To our knowledge, it remains unclear whether anti-inflammatory factors influences MSC activation. Our data show for the first time that IL-10 originated from anti-inflammatory macrophages contributes to potentiate immunomodulatory functions of MSC. We found that the ability of primed MSC to reduce TNF- $\alpha$ secretion from $M \Phi_{\mathrm{GM}}$ was enhanced by the content of TNF- $\alpha$ and IL-10 in $\mathrm{CM}_{\mathrm{M}}$. IL-10 alone was insufficient to potentiate MSC immunomodulation, but enhanced the priming effect of TNF- $\alpha$. These results indicate that MSC activation by IL-10 is dependent on TNF- $\alpha$ and suggest that IL-10 may act amplifying MSC activation by pro-inflammatory factors rather than as a priming factor. It is interesting to note that besides TNF- $\alpha$ and IL-10, CM contain a large range of soluble factors that may contribute to prime MSC. The optimal timing for MSC delivery remains uncertain and likely depends on the inflammatory environment associated with a specific disease or disorder. MSC administration at the early inflammatory stage, rather than after disease stabilization, seems to better guarantee the achievement of immunosuppressive activity in the case of acute GvHD [30]. However, the repair phase after acute myocardial infarction may be a more favorable time for MSC administration than during the acute injury phase, in which the hostile microenvironment could impair survival of transplanted cells [31]. Data herein suggest that 


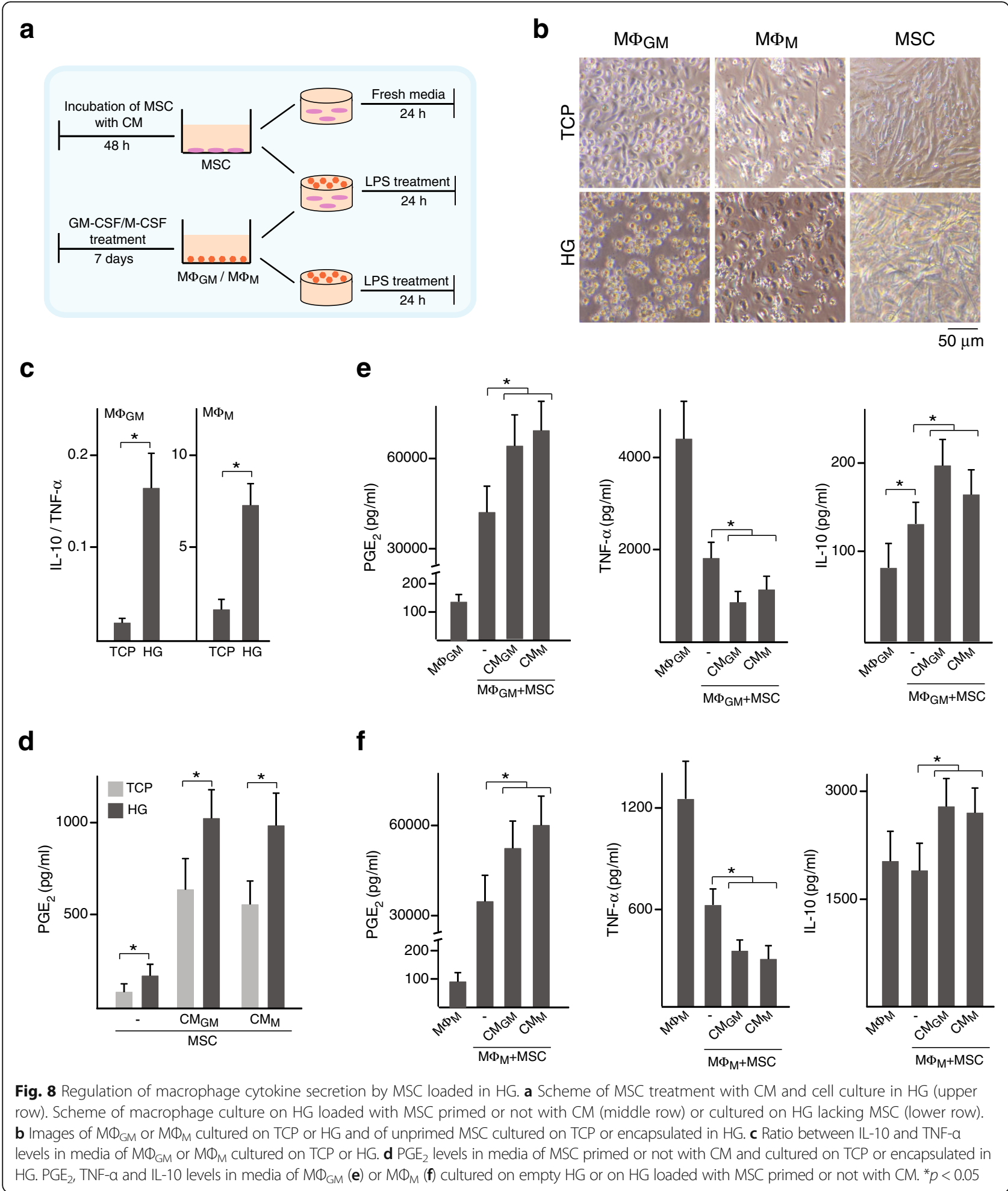

MSC may be effective in modulating the immune response when transplanted at the onset of resolution, when both pro-inflammatory and anti-inflammatory factors are secreted [6], facilitating an effective transition from the pro-inflammatory phase to tissue repair.
MSC-mediated immunomodulation involves a complex network of cytokines as well as cell to cell interactions. $\mathrm{PGE}_{2}$ exert anti-inflammatory effects on macrophages via the cyclic AMP-responsive element (CRE) binding proteins (CREB), which regulate the transcription rates of 
several immune-related genes, including TNF- $\alpha$ and IL-10, upon binding to CRE present in their promoter regions [32]. More recently, it has been described that IL-6 regulates anti-inflammatory macrophage polarization although underlying mechanism has not been fully elucidated [33, 34]. Using blocking antibodies, we demonstrated that IL-6 and $\mathrm{PGE}_{2}$ mediate the reduction in TNF- $\alpha$ secretion from $M \Phi_{\mathrm{GM}}$ in co-cultures with MSC. Interestingly, $\mathrm{CM}_{\mathrm{GM}}$ and $\mathrm{CM}_{\mathrm{M}}$, which contained high and low levels of pro-inflammatory factors, respectively, were similarly effective in stimulating $\mathrm{PGE}_{2}$ secretion by MSC. This effect may be explained by the IL-10-induced increase in $\mathrm{PGE}_{2}$ levels in the presence of low or high concentrations of TNF- $\alpha$. In this regard, IL-10 has been shown to enhance MSC activation by other inflammatory factors, as production of IFN- $\beta$ and IL- 10 by regulatory T cells synergistically induced expression of the immunoregulatory factor indoleamine 2,3-dioxygenase (IDO) at the mRNA level in MSC [35]. However, we did not detect IDO protein levels in the media of the various cultures and co-cultures of unprimed or primed MSC (data not shown). Changes in $\mathrm{PGE}_{2}$ secretion in co-cultures paralleled changes in COX2 mRNA levels in MSC indicating that production of this mediator was regulated at the mRNA level. The ability of primed MSC to further decrease TNF- $\alpha$ secretion by $M \Phi_{\mathrm{GM}}$ could be attributed to $\mathrm{PGE}_{2}$ but not to IL-6, as indicated in the experiments using neutralizing antibodies against these mediators. These data support the notion that MSC immunomodulatory potential is strongly related to the production of $\mathrm{PGE}_{2}$ and suggest that enhancement of the production of this immunoregulatory factor by anti-inflammatory stimuli occurs at the onset of resolution.

It is interesting to note that co-culturing $\mathrm{M} \Phi_{\mathrm{GM}}$ with unprimed MSC or with MSC primed with $\mathrm{CM}_{\mathrm{M}}$, which contained low levels of pro-inflammatory factors, failed to increase IL-10 secretion. MSC may require strong activation in a pro-inflammatory milieu to promote anti-inflammatory signatures in $\mathrm{M}_{\mathrm{GM}}$ as MSC primed with $\mathrm{CM}_{\mathrm{GM}}$ led to increased IL-10 levels in co-cultures. Recent in vitro and in vivo studies show that priming MSC with TNF- $\alpha$ at $10 \mathrm{ng} / \mathrm{ml}$ or higher doses favors macrophage polarization toward an anti-inflammatory phenotype [22, 29]. In fact, we detected that blocking TNF- $\alpha$ in $C_{\mathrm{GM}}$ reduced the ability of primed MSC to increase IL-10 secretion from $M \Phi_{\mathrm{GM}}$ and that priming MSC with $10 \mathrm{ng} / \mathrm{ml}$ TNF- $\alpha$ alone enhanced IL-10 levels in co-cultures. Reprograming macrophages to an antiinflammatory phenotype has been shown to be mediated by $\mathrm{PGE}_{2}$ [36]. Supporting this, neutralization of $\mathrm{PGE}_{2}$ in co-cultures of $M \Phi_{\mathrm{GM}}$ and MSC primed with $\mathrm{CM}_{\mathrm{GM}}$ reduced IL-10 levels. We speculate that $\mathrm{PGE}_{2}$ may promote IL-10 secretion from $M \Phi_{\mathrm{GM}}$ via the CREB signaling pathway, as described in cultures of mouse bone marrow macrophages [37]. Notably, priming MSC with $\mathrm{CM}_{\mathrm{M}}$, which increased $\mathrm{PGE}_{2}$ secretion, did not result in increased IL-10 production in co-cultures with $\mathrm{M} \Phi_{\mathrm{GM}}$, indicating that other factors secreted by MSC cooperate with $\mathrm{PGE}_{2}$ in macrophage phenotype switching.

Paracrine interactions between MSC and antiinflammatory macrophages have been scarcely investigated. MSC, primed or not with CM from macrophages, regulated TNF- $\alpha$ secretion from $M \Phi_{M}$ in a similar way to that observed in co-cultures with $M \Phi_{\mathrm{GM}}$ whereas IL-10 production showed different trends. As observed by others [38], IL-10 levels secreted by $M \Phi_{M}$ decreased after co-culturing with unprimed MSC. In contrast, $M \Phi_{M}$ maintained their anti-inflammatory traits when co-cultured with MSC primed with inflammatory factors. These results suggest that the cytokine environment strongly influences the ability of MSC to control anti-inflammatory functions of macrophages, allowing resolution of inflammation or preventing excessive anti-inflammatory activation that could impair tissue healing. Moreover, paracrine effects of MSC on $M \Phi_{M}$ could be regulated by anti-inflammatory factors secreted in the resolution of inflammation, as suggested by the data from experiments in which MSC were primed with a high concentration of IL-10. It should be mentioned that changes in IL-10 levels in co-cultures of $M \Phi_{M}$ were independent of the $\mathrm{PGE}_{2}$ content, suggesting that different signaling pathways regulate IL-10 production in pro-inflammatory and anti-inflammatory phenotypes.

Murine MSC upregulated the expression of MHC class II molecules in response to IFN- $\gamma$ and were rejected after implantation in immunocompetent MHC-mismatched mice [39-41]. In human MSC, the expression of both HLA classes I and II increased after treatment with IFN- $\gamma$ [20]. Our data show that treatment of MSC with CM increased surface expression of HLA class I but not of HLA class II, which could be attributed to an inhibitory effect of factors contained in the CM. For example, transforming growth factor- $\beta$ (TGF- $\beta$ ) has been shown to reduce IFN- $\gamma$-induced expression of HLA class II in human MSC [42]. One approach to improve stem cell-based therapies is the use of biomaterial carriers. Type I collagen HG have been successfully used as drug delivery vehicles for the treatment of long bone fracture and spinal fusion [43]. Moreover, collagen HG have been explored to increase MSC survival after implantation and prevent immune rejection in vivo [44]. We observed that collagen HG are instructive microenvironments for macrophages and MSC functions as well as for the crosstalk between both cell types. Collagen HG substantially decreased pro-inflammatory activation of $\mathrm{M} \Phi_{\mathrm{GM}}$ and potentiated anti-inflammatory activity of $M \Phi_{M}$ as compared to $2 \mathrm{D}$ substrates. Increased $\mathrm{PGE}_{2}$ secretion and greater immunomodulatory activity were observed in MSC cultured in 
three-dimensional (3D) topographies [45] or in spheroids [46], effects that were attributed to 3D disposition of MSC. Our data suggest that encapsulation of MSC in HG is an effective approach to enhance immunomodulatory properties of MSC. MSC in HG promoted antiinflammatory switching of $\mathrm{M} \Phi_{\mathrm{GM}}$, as indicated by marked reduction in TNF- $\alpha$ levels and increase in IL-10 production, and sustained $M \Phi_{M}$ activation characterized by high IL-10 secretion. Priming with CM conferred to MSC loaded in HG greater immunomodulatory potential, promoting $M \Phi_{\mathrm{GM}}$ polarization toward an anti-inflammatory phenotype and supporting $M \Phi_{M}$ anti-inflammatory activation. Enhanced immunoregulatory effects of primed MSC in HG were probably a result of the substantial increase in $\mathrm{PGE}_{2}$ levels compared to unprimed counterparts. Taken together, our results show that priming MSC with inflammatory factors originated from macrophages enhances their immunomodulatory potential. In fact, recent preclinical data supports the safety of IFN- $\gamma$-primed MSC infused in mice and their effectiveness to treat immune-related diseases [23, 47]. Encapsulation of primed MSC in HG could be an effective approach to improve their therapeutic efficacy upon implantation. Further studies are required to elucidate the in vivo immunomodulatory potential of primed MSC loaded in HG.

\section{Conclusions}

Factors secreted by pro-inflammatory and anti-inflammatory macrophages activate the immunomodulatory potential of MSC. This was attributed, at least in part, to the priming effect of TNF- $\alpha$ and was associated with an increase in $\mathrm{PGE}_{2}$ production by MSC. We identified that IL-10 secreted from anti-inflammatory macrophages, in combination with other inflammatory factors, activate MSC to secrete $\mathrm{PGE}_{2}$ and potentiate the priming effect of TNF- $\alpha$. Encapsulation of primed MSC in collagen HG enhances their immunoregulatory function, promoting anti-inflammatory activity of macrophages. These findings contribute to the understanding of the mechanisms by which macrophages polarization dynamics instruct MSC and may provide a basis for the development of novel strategies to enhance MSC immunoregulatory potential.

\section{Additional file}

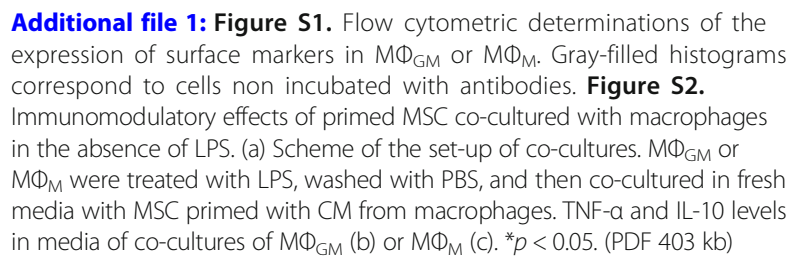

\section{Funding}

This work was supported by grants from Instituto Salud Carlos III (ISCIII)-Fondo Europeo de Desarrollo Regional (FEDER), MINECO-AES (PI15/00752 and PI15/ 01118) and Comunidad Autónoma de Madrid (CAM) (S2013/MIT-2862). LS is supported by a Miguel Servet contract from ISCIII-MINECO-AES-FEDER-FSE. NV is supported by Program 12 from CAM.

\section{Availability of data and materials}

The datasets generated and/or analyzed during the current study are available from the corresponding author on reasonable request.

\section{Authors' contributions}

LS conceived the project, designed the experiments, interpreted the results, and wrote the manuscript. FB, GV, and FJM conducted the experiments. EGC was involved in the design of the experiments and analysis of the data. NV helped to write and critically reviewed the manuscript. All authors reviewed, read, and approved the final manuscript.

\section{Ethics approval and consent to participate}

The protocol of this study was reviewed and approved by the Human Research Committee of Hospital Universitario La Paz (Date of Approval: 03/06/2015). All experiments were carried out in accordance with the approved guidelines and regulations.

\section{Consent for publication}

All authors have approved the submission for publication.

\section{Competing interests}

The authors declare that they have no competing interests.

\section{Publisher's Note}

Springer Nature remains neutral with regard to jurisdictional claims in published maps and institutional affiliations.

\section{Author details}

${ }^{1}$ Hospital Universitario La Paz-IdiPAZ, Paseo de la Castellana 261, 28046 Madrid, Spain. ${ }^{2}$ Centro de Investigación Biomédica en Red de Bioingeniería, Biomateriales y Nanomedicina, CIBER-BBN, Madrid, Spain. ${ }^{3}$ Departamento de Cirugía Ortopédica y Traumatología, Hospital Universitario La Paz-IdiPAZ, Madrid, Spain.

Received: 4 October 2018 Revised: 9 January 2019

Accepted: 27 January 2019 Published online: 13 February 2019

\section{References}

1. Galli S, Borregaard N, Wynn T. Phenotypic and functional plasticity of cells of innate immunity: macrophages, mast cells and neutrophils. Nat Immunol. 2011;12(11):1035-44.

2. Willenborg S, Lucas T, Van LG, Knipper JA, Krieg T, Haase I, et al. CCR2 recruits an inflammatory macrophage subpopulation critical for angiogenesis in tissue repair. Blood. 2012;120(3):613-25.

3. Daley JM, Brancato SK, Thomay AA, Reichner JS, Albina JE. The phenotype of murine wound macrophages. J Leukoc Biol. 2010;87(1):59-67.

4. Huang $R$, Wang $X$, Zhou $Y$, Xiao $Y$. RANKL-induced $M 1$ macrophages are involved in bone formation. Bone Res. 2017:5:1-13.

5. Sica A, Mantovani A. Macrophage plasticity and polarization: in vivo veritas. J Clin Invest. 2012;122(3):787-95.

6. Sugimoto MA, Sousa LP, Pinho V, Perretti M, Teixeira MM. Resolution of inflammation: what controls its onset? Front Immunol. 2016;7:160.

7. Mirza R, DiPietro LA, Koh TJ. Selective and specific macrophage ablation is detrimental to wound healing in mice. Am J Pathol. 2009;175(6):2454-62.

8. Sindrilaru A, Peters T, Wieschalka S, Baican C, Baican A, Peter H, et al. An unrestrained proinflammatory M1 macrophage population induced by iron impairs wound healing in humans and mice. J Clin Invest. 2011;121(3):985-97.

9. Eming SA, Wynn TA, Martin P. Inflammation and metabolism in tissue repair and regeneration. Science. 2017;356(6342):1026-30.

10. Bernardo ME, Fibbe WE. Mesenchymal stromal cells: sensors and switchers of inflammation. Cell Stem Cell. 2013;13(4):392-402.

11. Ren G, Zhang L, Zhao X, Xu G, Zhang Y, Roberts Al, et al. Mesenchymal stem cell-mediated immunosuppression occurs via concerted action of chemokines and nitric oxide. Cell Stem Cell. 2008;2(2):141-50. 
12. Li W, Ren G, Huang Y, Su J, Han Y, Li J, et al. Mesenchymal stem cells: a double-edged sword in regulating immune responses. Cell Death Differ. 2012;19(9):1505-13.

13. Renner $P$, Eggenhofer $E$, Rosenauer A, Popp FC, Steinmann JF, Slowik $P$, et al. Mesenchymal stem cells require a sufficient, ongoing immune response to exert their immunosuppressive function. Transplant Proc. 2009; 41(6):2607-11.

14. Karin $\mathrm{M}$, Clevers $\mathrm{H}$. Reparative inflammation takes charge of tissue regeneration. Nature. 2016;529(7586):307-15.

15. Novak ML, Koh TJ. Macrophage phenotypes during tissue repair. J Leukoc Biol. 2013;93(6):875-81.

16. Galipeau J, Sensébé L. Mesenchymal stromal cells: clinical challenges and therapeutic opportunities. Cell Stem Cell. 2018;22(6):824-33.

17. Lohan P, Treacy O, Griffin MD, Ritter T, Ryan AE. Anti-donor immune responses elicited by allogeneic mesenchymal stem cells and their extracellular vesicles: are we still learning? Front Immunol. 2017;8:1626

18. Liu M, Zeng X, Ma C, Yi H, Ali Z, Mou X, et al. Injectable hydrogels for cartilage and bone tissue engineering. Bone Res. 2017;5:17014.

19. Murphy WL, McDevitt TC, Engler AJ. Materials as stem cell regulators. Nat Mater. 2014;13(6):547-57.

20. Le BK, Tammik C, Rosendahl K, Zetterberg E, Ringdén O. HLA expression and immunologic properties of differentiated and undifferentiated mesenchymal stem cells. Exp Hematol. 2003;31(10):890-6.

21. Berglund AK, Fortier LA, Antczak DF, Schnabel LV. Immunoprivileged no more: measuring the immunogenicity of allogeneic adult mesenchymal stem cells. Stem Cell Res Ther. 2017;8(1):1-7.

22. Aktas E, Chamberlain CS, Saether EE, Duenwald-Kuehl SE, KondratkoMittnacht J, Stitgen M, et al. Immune modulation with primed mesenchymal stem cells delivered via biodegradable scaffold to repair an Achilles tendon segmental defect. J Orthop Res. 2017;35(2):269-80.

23. Kim DS, Jang IK, Lee MW, Ko YJ, Lee DH, Lee JW, et al. Enhanced immunosuppressive properties of human mesenchymal stem cells primed by interferon- $\gamma$. EBioMedicine. 2018;28:261-73.

24. Saether EE, Chamberlain CS, Aktas E, Leiferman EM, Brickson SL, Vanderby R. Primed mesenchymal stem cells alter and improve rat medial collateral ligament healing. Stem Cell Rev Reports. 2016;12(1):42-53.

25. Duijvestein $M$, Wildenberg ME, Welling MM, Hennink S, Molendijk I, van ZVL, et al. Pretreatment with interferon- $\gamma$ enhances the therapeutic activity of mesenchymal stromal cells in animal models of colitis. Stem Cells. 2011; 29(10):1549-58.

26. Herrmann JL, Wang Y, Abarbanell AM, Weil BR, Tan J, Meldrum DR. Preconditioning mesenchymal stem cells with transforming growth factoralpha improves mesenchymal stem cell-mediated cardioprotection. Shock. 2010;33(1):24-30

27. François M, Romieu-Mourez R, Li M, Galipeau J. Human MSC suppression correlates with cytokine induction of indoleamine 2,3-dioxygenase and bystander M2 macrophage differentiation. Mol Ther. 2012;20(1):187-95.

28. Gray A, Maguire T, Schloss R, Yarmush ML. Identification of IL-1 $\beta$ and LPS as optimal activators of monolayer and alginate-encapsulated mesenchymal stromal cell immunomodulation using design of experiments and statistical methods. Biotechnol Prog. 2015;31(4):1058-70.

29. Lin T, Pajarinen J, Nabeshima A, Lu L, Nathan K, Jämsen E, et al. Preconditioning of murine mesenchymal stem cells synergistically enhanced immunomodulation and osteogenesis. Stem Cell Res Ther. 2017;8(1):277.

30. Wei $X$, Yang $X$, Han Z, Qu F, Shao L, Shi Y. Mesenchymal stem cells: a new trend for cell therapy. Acta Pharmacol Sin. 2013;34(6):747-54.

31. Liu B, Duan CY, Luo CF, Ou CW, Wu ZY, Zhang JW, et al. Impact of timing following acute myocardial infarction on efficacy and safety of bone marrow stem cells therapy: a network meta-analysis. Stem Cells Int. 2016;2016:1-11.

32. Avni D, Ernst $\mathrm{O}$, Philosoph A, Zor T. Role of CREB in modulation of TNFa and IL-10 expression in LPS-stimulated RAW264.7 macrophages. Mol Immunol. 2010;47(7-8):1396-403.

33. Mauer J, Chaurasia B, Goldau J, Vogt MC, Ruud J, Nguyen KD, et al. Interleukin-6 signaling promotes alternative macrophage activation to limit obesity-associated insulin resistance and endotoxemia. Nat Immunol. 2012;29(6):997-1003.

34. Braune J, Weyer U, Hobusch C, Mauer J, Brüning JC, Bechmann I, et al, IL-6 regulates $\mathrm{M} 2$ polarization and local proliferation of adipose tissue macrophages in obesity. J Immunol. 2017;198(7):2927-34

35. Lim JY, Im Kl, Lee ES, Kim N, Nam YS, Jeon YW, et al. Enhanced immunoregulation of mesenchymal stem cells by IL-10-producing type 1 regulatory T cells in collagen-induced arthritis. Sci Rep. 2016;6(1):26851.
36. Németh K, Leelahavanichkul A, Yuen PST, Mayer B, Parmelee A, Doi K, et al. Bone marrow stromal cells attenuate sepsis via prostaglandin $\mathrm{E}(2)$ dependent reprogramming of host macrophages to increase their interleukin-10 production. Nat Med. 2009;15(1):42-9.

37. Luan B, Yoon Y-S, Le LJ, Kaestner KH, Hedrick S, Montminy M. CREB pathway links PGE2 signaling with macrophage polarization. Proc Natl Acad Sci U S A. 2015;112(51):15642-7.

38. Vasandan AB, Jahnavi S, Shashank C, Prasad P, Kumar A, Prasanna SJ. Human mesenchymal stem cells program macrophage plasticity by altering their metabolic status via a PGE2-dependent mechanism. Sci Rep. 2016;6(1):38308.

39. Stagg J, Pommey S, Eliopoulos N, Galipeau J. Interferon-gamma-stimulated marrow stromal cells: a new type of nonhematopoietic antigen-presenting cell. Blood. 2006:107(6):2570-7.

40. Eliopoulos N, Stagg J, Lejeune L, Pommey S, Galipeau J. Allogeneic marrow stromal cells are immune rejected by $\mathrm{MHC}$ class 1 - and class $\mathrm{II}$-mismatched recipient mice. Blood. 2005;106(13):4057-65.

41. Polchert D, Sobinsky J, Douglas G, Kidd M, Moadsiri A, Reina E, et al. IFNgamma activation of mesenchymal stem cells for treatment and prevention of graft versus host disease. Eur J Immunol. 2008;38(6):1745-55.

42. Romieu-Mourez R, Francois M, Boivin M-N, Stagg J, Galipeau J. Regulation of MHC class II expression and antigen processing in murine and human mesenchymal stromal cells by IFN- $\gamma$, TGF- $\beta$, and cell density. J Immunol. 2007;179(3):1549-58

43. Li J, Mooney DJ. Designing hydrogels for controlled drug delivery. Nat Rev Mater. 2016;1(12):1-18

44. Burdick JA, Mauck RL, Gerecht S. To serve and protect: hydrogels to improve stem cell-based therapies. Cell Stem Cell. 2016;18(1):13-5.

45. Vallés $G$, Bensiamar F, Crespo L, Arruebo M, Vilaboa N, Saldaña L. Topographical cues regulate the crosstalk between MSCs and macrophages. Biomaterials. 2015;37:124-33.

46. Ylöstalo JH, Bartosh TJ, Coble K, Prockop DJ. Human mesenchymal stem/ stromal cells cultured as spheroids are self-activated to produce prostaglandin E2 that directs stimulated macrophages into an antiinflammatory phenotype. Stem Cells. 2012;30(10):2283-96.

47. Guess AJ, Daneault B, Wang R, Bradbury H, KMD LP, Fitch J, et al. Safety profile of good manufacturing practice manufactured interferon $\gamma$-primed mesenchymal stem/stromal cells for clinical trials. Stem Cells Transl Med. 2017:6(10):1868-79.
Ready to submit your research? Choose BMC and benefit from:
- fast, convenient online submission
- thorough peer review by experienced researchers in your field
- rapid publication on acceptance
- support for research data, including large and complex data types
- gold Open Access which fosters wider collaboration and increased citations
- maximum visibility for your research: over $100 \mathrm{M}$ website views per year
At $\mathrm{BMC}$, research is always in progress. 